\title{
Hypothyroidism increases cyclooxygenase-2 levels and pro-inflammatory response and decreases cell proliferation and neuroblast differentiation in the hippocampus
}

\author{
SUNG MIN NAM ${ }^{1,2}$, JONG WHI KIM ${ }^{1}$, DAE YOUNG YOO ${ }^{1}$, HYO YOUNG JUNG ${ }^{1}$, JIN YOUNG CHUNG ${ }^{3}$, \\ DAE WON KIM ${ }^{4}$, IN KOO HWANG ${ }^{1}$ and YEO SUNG YOON ${ }^{1}$
}

\begin{abstract}
${ }^{1}$ Department of Anatomy and Cell Biology, College of Veterinary Medicine and Research Institute for Veterinary Science, Seoul National University, Seoul 08826; ${ }^{2}$ Department of Anatomy, College of Veterinary Medicine, Konkuk University, Seoul 05030; ${ }^{3}$ Department of Veterinary Internal Medicine and Geriatrics, College of Veterinary Medicine, Kangwon National University, Chuncheon, Gangwon 24341; ${ }^{4}$ Department of Biochemistry and Molecular Biology, Research Institute of Oral Sciences, College of Dentistry, Gangneung-Wonju National University, Gangneung, Gangwon 25457, Republic of Korea
\end{abstract}

Received June 13, 2016; Accepted February 23, 2017

DOI: $10.3892 / \mathrm{mmr} .2018 .8605$

\begin{abstract}
The present study investigated the effects of hypothyroidism on cyclooxygenase-2 (COX-2) and pro-inflammatory cytokines in the dentate gyrus to elucidate the roles of COX-2 in the hypothyroid hippocampus. Hypothyroidism was induced in rats by treating with $0.03 \%$ 2-mercapto-1-methyl-imidazole dissolved in drinking water for 5 weeks. The animals were sacrificed at 12 weeks of age. Hypothyroidism rats exhibited decreased triiodothyronine and thyroxine levels in the serum, while the levels of thyroid-stimulating hormone and the weight of thyroid glands were significantly higher in the hypothyroid rats compared with those in the vehicle-treated group. COX-2 immunoreactivity was significantly increased in the hippocampal CA2/3 region and the dentate gyrus compared with the vehicle-treated group. Levels of pro-inflammatory cytokines including interleukin (IL)-1 $\beta$, IL-6 and tumor necrosis factor- $\alpha$ were significantly higher in the hippocampal homogenates of hypothyroid rats. Cell proliferation and neuroblast differentiation based on Ki67 and doublecortin immunohistochemistry were decreased in the dentate gyrus of hypothyroid rats compared with those in the vehicle-treated group. These results suggested that hypothyroidism-mediated COX-2 expression affected hippocampal plasticity by upregulating the levels of pro-inflammatory cytokines in the hippocampus. Therefore,
\end{abstract}

Correspondence to: Professor Yeo Sung Yoon or Professor In Koo Hwang, Department of Anatomy and Cell Biology, College of Veterinary Medicine and Research Institute for Veterinary Science, Seoul National University, 1 Gwanak-ro, Seoul 08826, Republic of Korea

E-mail: ysyoon@snu.ac.kr

E-mail: vetmed2@snu.ac.kr

Key words: cyclooxygenase-2, hippocampus, hypothyroidism, neurogenesis, pro-inflammatory cytokine
COX-2 may be suggested as a candidate molecule for preventing hypothyroidism-induced neurological side effects.

\section{Introduction}

The thyroid hormone triiodothyronine $\left(\mathrm{T}_{3}\right)$ and its prohormone, thyroxine $\left(\mathrm{T}_{4}\right)$ are produced by the thyroid gland and serve an important role in metabolism in the body, including in the central nervous system $(1,2)$. The hippocampus has a high density of thyroid hormone receptors and adult onset of hypothyroidism causes damage to morphology and function in the hippocampus (3), suggesting that it is an important target for thyroid hormones in the brain (4). Hypothyroidism also reduces the proliferation of cells in the hippocampal dentate gyrus in the adult brain $(5,6)$. Adult-onset hypothyroidism in rats facilitates the hyper-phosphorylation of tau protein and reduces the synaptic plasticity marker proteins, including neurogranin, extracellular signal-regulated kinases, glycogen synthase kinase $3 \beta$ and phosphorylated cAMP response element-binding protein (7).

Cyclooxygenase (COX) is responsible for the formation of prostanoids, including thromboxane and prostaglandins, and provides anti-inflammatory functions. COX-1 is produced constitutively, whereas $\mathrm{COX}-2$ production is inducible following insult, including inflammation $(8,9)$. COX-2 has been investigated since it is also constitutively expressed in the brain $(10,11)$, particularly in the cerebral cortex and hippocampus (12). Of particular interest, the expression of COX-2 in the hippocampus regulates adult hippocampal neurogenesis in the dentate gyrus in normal and brain damage conditions. However, there are no reports that have determined the correlation between hypothyroidism and COX-2 expression in the hippocampus, although hypothyroidism affects hippocampal function in rats. The present study therefore investigated the effects of hypothyroidism on the levels of COX-2 and certain pro-inflammatory cytokines including interleukin (IL)-1 $\beta$, IL-6 and tumor necrosis factor- $\alpha(\mathrm{TNF}-\alpha)$ in the hippocampus 
to elucidate the roles of COX-2-associated neuro-inflammation and hippocampal neurogenesis in hypothyroidism model rats.

\section{Materials and methods}

Experimental animals. A total of 20 male Sprague-Dawley rats (6-week-old; body weight, 180-200 g) were purchased from Orient Bio, Inc. (Seongnam, Korea). They were housed under standard conditions with adequate temperature $\left(22^{\circ} \mathrm{C}\right)$ and humidity (60\%) control, a 12-h light: 12-h dark cycle and free access to food and water. The handling and care of the animals conformed to the guidelines established to comply with current international laws and policies stated in the NIH Guide for the Care and Use of Laboratory Animals, NIH Publication, 1996 (13) and were approved by the Institutional Animal Care and Use Committee of Seoul National University (Seoul, Korea). All the experiments were conducted with an effort to minimize the number of animals used and the suffering caused by the procedures employed in the present study.

Experimental design. To investigate the effects of 2-mercapto-1-methyl-imidazole (methimazole)-induced hypothyroidism on COX-2 expression in the rat hippocampus, rats were randomly divided into euthyroid and hypothyroid groups ( $n=10$ in each group). At 7 weeks of age, $0.03 \%$ methimazole ( 12 mg/day; Sigma-Aldrich; Merck KGaA, Darmstadt, Germany) was administered to the hypothyroid group in drinking water for 5 weeks to prevent thyroid hormone synthesis by inhibited coupling and iodination (14).

Serum levels of thyroid-stimulating hormones (TSH) and thyroid hormones. To confirm the hypothyroid state, blood specimens at morning (9:00-11:00 a.m.) were drawn from the vehicle and hypothyroid groups following sacrifice at the age of 12 weeks for analysis. The serum circulating $\mathrm{TSH}$, free $\mathrm{T}_{3}$ and $\mathrm{T}_{4}$ levels were measured to determine thyroid function in these rats using Accu Bind Vast enzyme-linked immunosorbent assay (ELISA) kit (cat. no. 8025-300D; Monobind, Inc., Lake Forest, CA, USA).

Tissue processing for histology. For histology, the animals ( $\mathrm{n}=5$ in each group) were anesthetized with $1 \mathrm{~g} / \mathrm{kg}$ urethane (Sigma-Aldrich; Merck KGaA) at various time points following surgery. Animals were perfused transcardially with 0.1 M phosphate-buffered saline (PBS, $\mathrm{pH}$ 7.4), followed by $4 \%$ paraformaldehyde in $0.1 \mathrm{M}$ PBS ( $\mathrm{pH} 7.4)$. Brains were removed and post-fixed in the same fixative for $12 \mathrm{~h}$ prior to undergoing cryoprotection via overnight storage in $30 \%$ sucrose. Serial coronal brain sections $(30 \mu \mathrm{m})$ were produced using a cryostat (Leica Microsystems GmbH, Wetzlar, Germany) and collected into 6-well plates containing PBS. To ensure that the histochemical and immunohistochemical data were comparable between groups, sections were carefully processed under parallel conditions. Tissue sections located $120 \mu \mathrm{m}$ apart from each other were selected from an area between $3.00 \mathrm{~mm}$ and $4.08 \mathrm{~mm}$ posterior to the bregma, as defined by a rat brain atlas (15).

Immunohistochemistry for COX-2, Ki67 and doublecortin $(D C X)$. A total of four sections from tissue sections located
$120 \mu \mathrm{m}$ apart from each other were sequentially incubated with $0.3 \%$ hydrogen peroxide $\left(\mathrm{H}_{2} \mathrm{O}_{2}\right)$ in PBS for $30 \mathrm{~min}$ and $10 \%$ normal horse serum (cat. no. S-2000; Vector Laboratories, Inc., Burlingame, CA, USA) in 0.05 M PBS for $30 \mathrm{~min}$. Sections were then incubated with a rabbit anti-COX-2 antibody (cat. no. 160106; 1:200; Cayman, Ann Arbor, MI, USA), rabbit anti-Ki67 antibody (cat. no. ab15580; 1:1,000; Abcam, Cambridge, UK), or goat anti-DCX antibody (cat. no. sc-8066; 1:50; Santa Cruz Biotechnology, Inc., Dallas, TX, USA) overnight at room temperature. Sections were then incubated for $2 \mathrm{~h}$ at $25^{\circ} \mathrm{C}$ with biotinylated horse anti-rabbit IgG (cat. no. BA-1100; 1:200; Vector Laboratories, Inc.) or horse anti-goat IgG (cat. no. BA-9500; 1:200; Vector Laboratories, Inc.), followed by a streptavidin-peroxidase complex (cat. no. SA-5004; 1:200; Vector Laboratories, Inc.). Immunostaining was visualized by reaction with diaminobenzidine in $0.1 \mathrm{M}$ Tris- $\mathrm{HCl}$ buffer ( $\mathrm{pH}$ 7.2). Sections were dehydrated and mounted on gelatin-coated slides in Canada balsam (Kanto Chemical Co., Ltd., Tokyo, Japan).

To quantify the COX-2 immunoreactivity, analysis of the dentate gyrus and hippocampal CA3 region was performed using an image analysis system (Optimas version 6.5; Cyber Metrics Corporation, Scottsdale, AZ, USA) and ImageJ software version 1.5 (National Institutes of Health, Bethesda, MD, USA). Digital images of the mid-point of the dentate gyrus and hippocampal CA3 region were captured with a BX51 light microscope (Olympus Corporation, Tokyo, Japan) equipped with a digital camera (DP72; Olympus Corporation) connected to a computer monitor. Images were calibrated into an array of $512 \times 512$ pixels corresponding to a tissue area of $1,200 \times 900 \mu \mathrm{m}$ (primary magnification, x100). Each pixel resolution was 256 gray levels and the intensity of COX-2 immunoreactivity was evaluated by relative optical density (ROD), which was obtained following transformation of the mean gray level using the formula: ROD $=\log (256 /$ mean gray level). ROD of background staining was determined in unlabeled portions of the sections using Photoshop CC 2015 software (Adobe Systems, Inc., San Jose, CA, USA) and this value was subtracted to correct for nonspecific staining, using ImageJ. Data are expressed as a percentage of the euthyroid group values (set to $100 \%$ ).

Ki67- and DCX-positive cell counts were performed for each section of the dentate gyrus using an image analysis system equipped with a computer-based CCD camera (Optimas version 6.5; Cyber Metrics Corporation, Scottsdale, AZ, USA). Cell counts from all the sections of all the rats were averaged.

ELISA for IL-1 $\beta, I L-6$ and TNF- $\alpha$. To confirm changes in TNF- $\alpha$, IL- $1 \beta$ and IL- 6 level in the hippocampus, animals in the euthyroid and hypothyroid groups ( $n=5$ per group) were sacrificed and used for ELISA analysis. Following sacrifice and removal of the hippocampus, the hippocampal tissues were homogenized in ice-cold $50 \mathrm{mM}$ sodium phosphate buffer ( $\mathrm{pH}$ 7.4) containing 0.1 mM EDTA using a glass-Teflon homogenizer (Heidolph Silent Crusher M; Heidolph Instruments $\mathrm{GmbH}$, Schwabach, Germany). The supernatant was separated by centrifugation at $1,000 \mathrm{x}$ g for $20 \mathrm{~min}$ at $4^{\circ} \mathrm{C}$. IL-1 $\beta$, IL- 6 and TNF- $\alpha$ were measured in the supernatant of homogenized hippocampal tissue by using ELISA kits (cat. nos. MBS175941, MBS355410 and MBS2502004 respectively; 

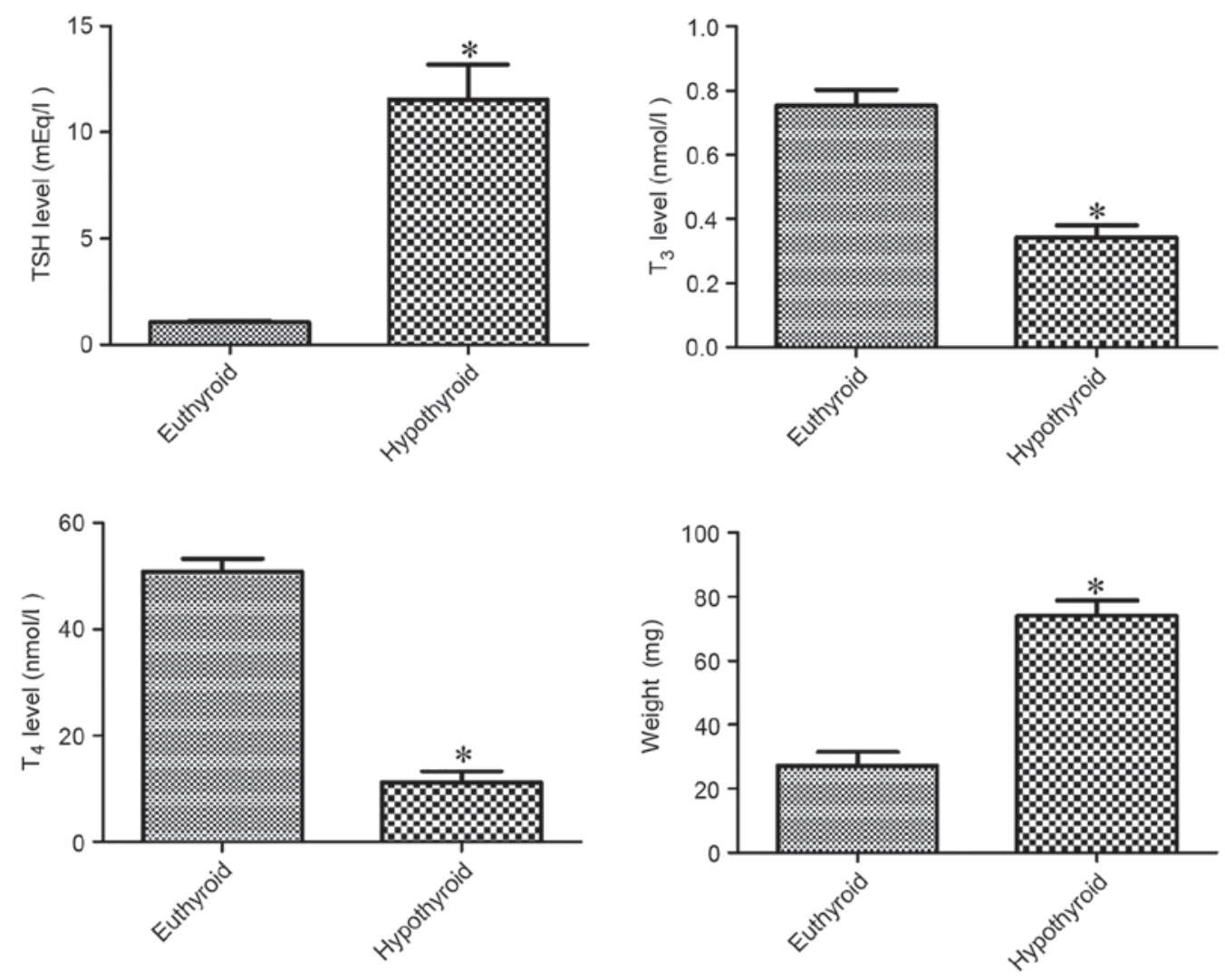

Figure 1. Changes in circulating TSH, $\mathrm{T}_{3}$ and $\mathrm{T}_{4}$ levels in addition to weights of thyroid glands in the euthyroid and hypothyroid rats. Differences between the means were analyzed using Student's t-test ( $\mathrm{n}=5$ per group; " $\mathrm{P}<0.05$ vs. euthyriod)'). The bars represent the mean \pm standard error of the mean. TSH, thyroid stimulating hormone; $\mathrm{T} 3$, triiodothyronine; T4, thyroxine.

BioSource International, Inc., Camarillo, CA, USA). The procedures were carried out according to the manufacturer's protocols. IL-1 $\beta$, IL-6 and TNF- $\alpha$ were determined from a standard curve and their levels were expressed in $\mathrm{ng} / \mathrm{mg}$ total protein.

Statistical analysis. The data are presented as mean \pm standard error of the mean. Differences among the means were statistically analyzed by a Student's t-test, using GraphPad Prism version 5.01 software (GraphPad Software, Inc., La Jolla, CA, USA). $\mathrm{P}<0.05$ was considered to indicate a statistically significant difference.

\section{Results}

Effects of hypothyroidism on phenotypes in blood and organs. At 12 weeks of age, hypothyroidism significantly decreased serum $\mathrm{T}_{3}$ and $\mathrm{T}_{4}$ levels by 45.4 and $22.1 \%$, respectively, compared with vehicle-treated group. By contrast, TSH level was significantly higher (11-fold) in the hypothyroid rats compared with the vehicle-treated group. The weight of the thyroid gland was significantly higher (2.72-fold) in the hypothyroid rats compared with the vehicle-treated group (Fig. 1).

Effects of hypothyroidism on COX-2 expression in the hippocampus. At 12 weeks of age, COX-2 immunoreactivity was detectable in the granule cell layer, polymorphic layer and CA4 region of the dentate gyrus (Fig. 2A) in addition to the stratum pyramidale of the hippocampal CA3 region (Fig. 2B).
COX-2 immunoreactivity was significantly higher in these regions in the hypothyroid rats compared with the euthyroid rats (Fig. 2C).

Effects of hypothyroidism on pro-inflammatory cytokines. At 12 weeks of age, hypothyroidism significantly increased the levels of IL-1 $\beta$, IL- 6 and TNF- $\alpha$, as detected by ELISA, compared with the euthyroid group (Fig. 3).

Effects of hypothyroidism on cell proliferation. At 12 weeks of age, Ki67 immunoreactivity was observed in the nuclei located in the subgranular zone of the dentate gyrus (Fig. 4A and B). Hypothyroidism significantly reduced the number of Ki67-positive nuclei in the dentate gyrus compared with the euthyroid group (Fig. 4C).

Effects of hypothyroidism on neuroblast differentiation. DCX-immunoreactive neuroblasts were observed in the cytoplasm and dendrites located in the subgranular zone of the dentate gyrus and extending to the molecular layer of the dentate gyrus, respectively (Fig. 5A and B). Hypothyroidism significantly reduced the number of DCX-immunoreactive neuroblasts and the complexity of dendrites compared with the euthyroid group (Fig. 5C).

\section{Discussion}

Adult hypothyroidism increases amyloid $\beta$ precursor protein (APP) gene expression and facilitates the amyloidogenic 
A

A
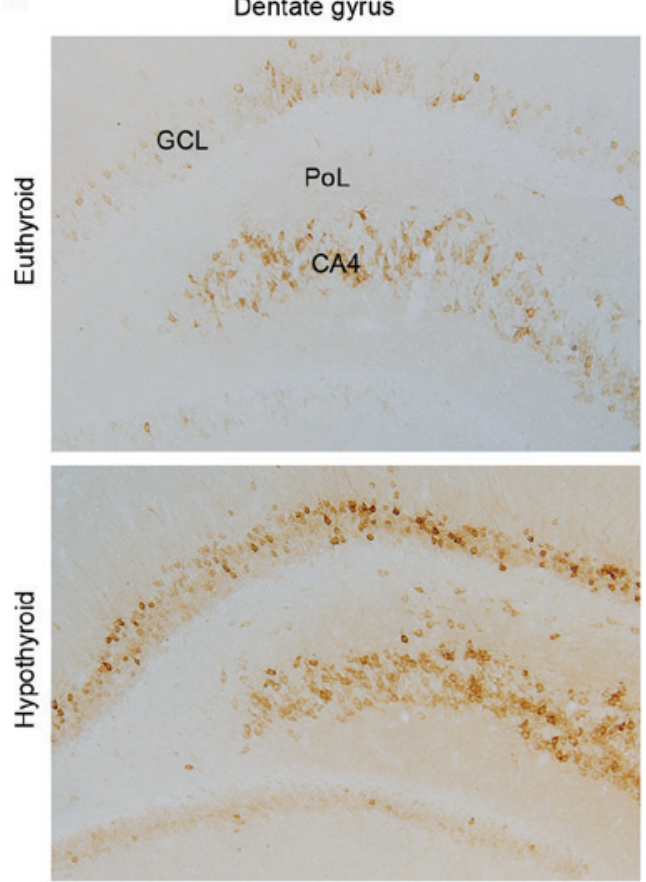

B
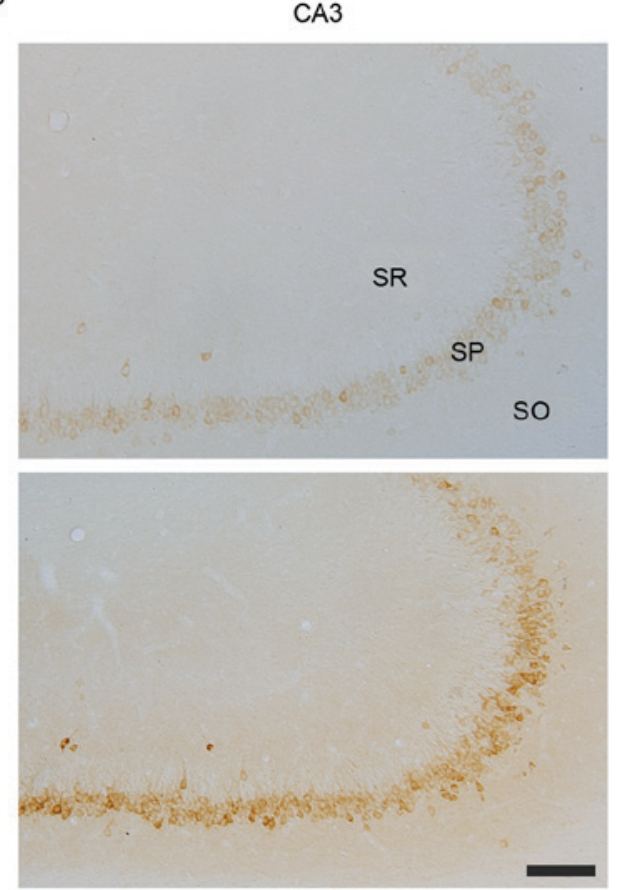

$\mathbf{B}$ Hypothyroid

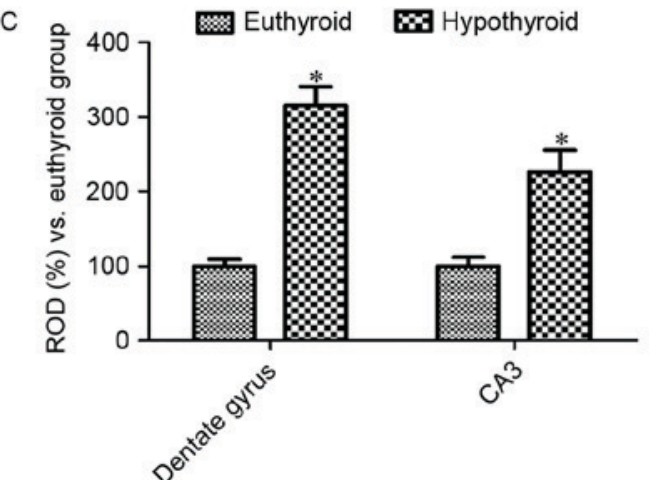

Figure 2. COX-2 immunoreactivity in the (A) dentate gyrus and (B) CA3 region of euthyroid and hypothyroid rats. COX-2 immunoreactivity is identified in the GCL, PoL and CA4 region of dentate gyrus in addition to in the SP of the CA3 region. COX-2 immunoreactivity is dense in the hypothyroid rats compared with the euthyroid rats. Scale bar, $100 \mu \mathrm{m}$. (C) The ROD, expressed as a percentage of the value in the euthyroid group of COX-2 immunoreactivity in the dentate gyrus and hippocampal CA3 region per section. Differences between the means were analyzed using Student's t-test ( $\mathrm{n}=5$ per group; $\mathrm{P}<0.05$ vs. euthyriod). The bars represent the mean \pm standard error of the mean. GCL, granule cell layer; PoL, polymorphic layer; SP, SO, stratum oriens; SR, stratum radiatum; SP, stratum pyramidale; ROD, relative optical density.
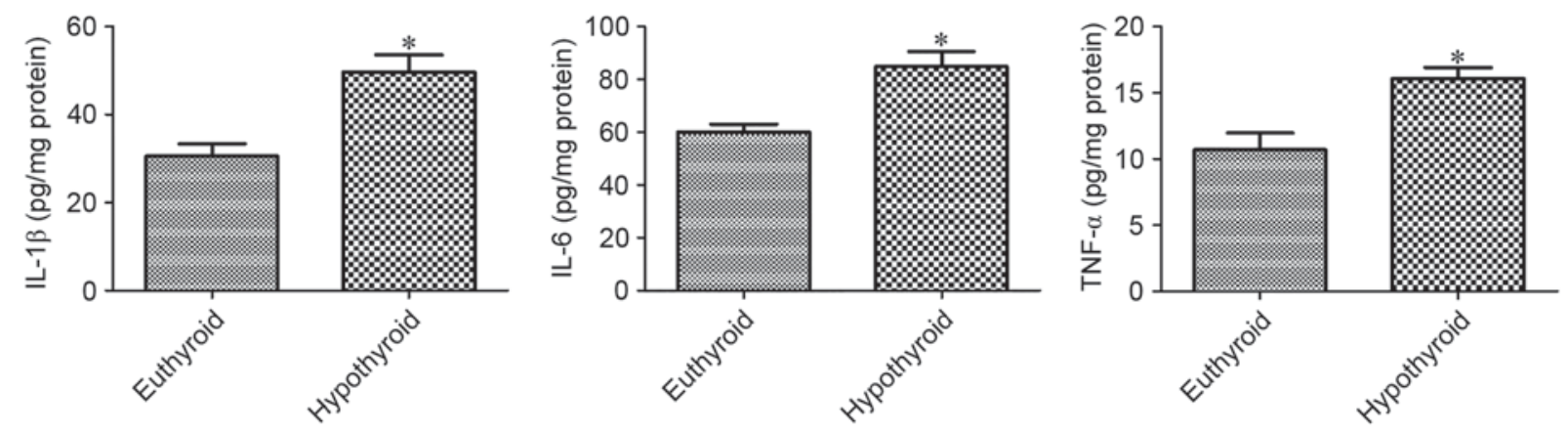

Figure 3. Enzyme-linked immunosorbent assay of IL-1 $\beta$, IL-6 and TNF- $\alpha$ in hippocampal homogenates of euthyroid and hypothyroid rats (n=5 per group; ${ }^{*} \mathrm{P}<0.05$ vs. euthyroid). The bars represent the mean \pm standard error of the mean. IL, interleukin; TNF- $\alpha$, tumor necrosis factor- $\alpha$.

pathway of APP processing in the rat hippocampus $(16,17)$ In Alzheimer patients, localized hypothyroidism has been identified in the hippocampus $(18,19)$. In the present study, hypothyroidism was induced by methimazole and the hypothyroid state was assessed by serum TSH, $\mathrm{T}_{3}$ and $\mathrm{T}_{4}$ levels in addition to weight of the thyroid gland. Methimazole treatment 
A

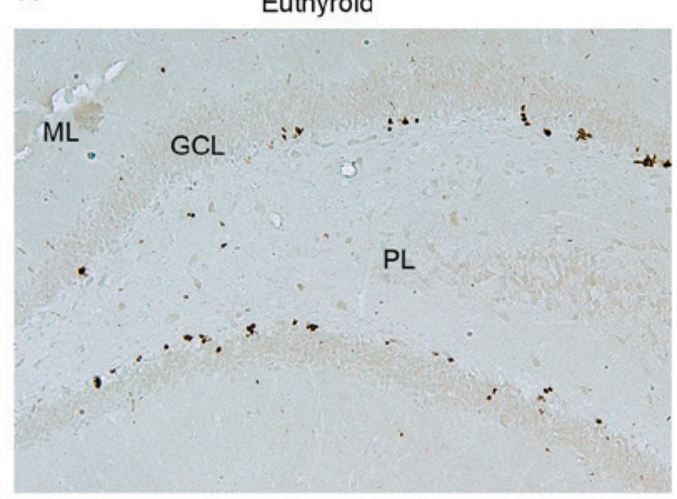

B

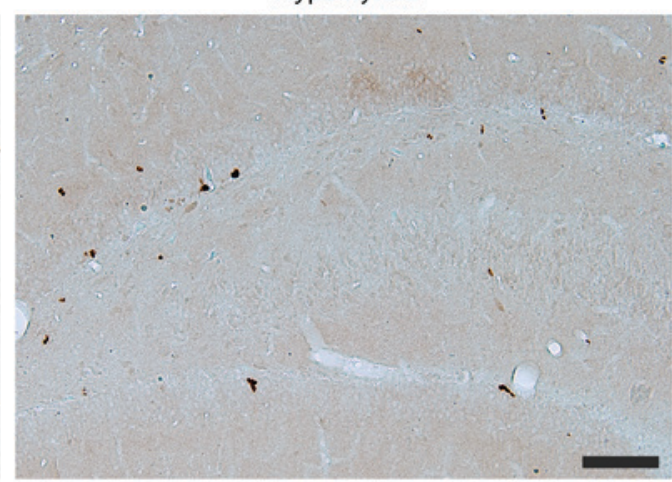

C

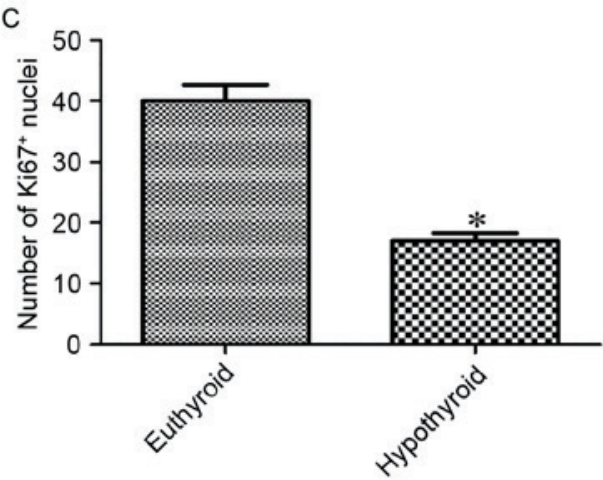

Figure 4. Ki67 immunoreactivity in the dentate gyrus of (A) euthyroid and (B) hypothyroid rats. Ki67 positive nuclei are identified in the subgranular zone of dentate gyrus. There are fewer Ki67 positive nuclei in the hypothyroid group than in the euthyroid group. Scale bar, $100 \mu \mathrm{m}$. (C) Number of Ki67-positive nuclei per section for each group. Differences between the means were analyzed using Student's $t$-test ( $\mathrm{n}=5$ per group; ${ }^{*} \mathrm{P}<0.05$ vs. euthyroid). The bars represent the mean \pm standard error of the mean. GCL, granule cell layer; ML, molecular layer; PL, polymorphic layer.

significantly reduced serum $\mathrm{T}_{3}$ and $\mathrm{T}_{4}$ levels, while serum $\mathrm{TSH}$ level in addition to thyroid gland weight were significantly increased.

The changes in COX-2 levels in the hippocampus was investigated as COX-2 has dual functions in the synaptic plasticity and inflammation in the hippocampus. In certain types of brain injury, COX-2 serves multiple roles in the regulation of adult hippocampal neurogenesis in the dentate gyrus (20-22). Knockdown of COX-2 significantly reduces the number of proliferating cells and differentiated neuroblasts in the dentate gyrus compared with wild-type littermates $(21,22)$. In a previous study (23), we demonstrated that the blocking constitutive COX-2 in the hippocampus by celecoxib, a COX-2 inhibitor, significantly decreased cell proliferation and neuroblast differentiation in the dentate gyrus. Hypothermia protects neurons from ischemic damage and produces a dramatic increase in COX-2 immunoreactivity in the granule cells of the dentate gyrus within $4 \mathrm{~h}$ after ischemia compared with normothermic animals (24). However, the present study observed a significant reduction in cell proliferation and neuroblast differentiation in the dentate gyrus. This result is supported by previous studies $(5,6,25)$ that indicate that postnatal or adult onset hypothyroidism decreases neurogenesis in the dentate gyrus. Thus, it is hypothesized that the upregulation of COX-2 may be closely associated with an increase in pro-inflammatory cytokines, including IL- $1 \beta$, IL- 6 and TNF- $\alpha$ in the hippocampal homogenates.

The present study noted a significant increase in IL-1 $\beta$ expression and IL- 6 and TNF- $\alpha$ levels in the hippocampal homogenates. This result is consistent with that of a previous study (7), which demonstrated that hypothyroidism induced by propylthiouracil for 5 weeks significantly increased the mRNA levels of pro-inflammatory cytokines, including IL-1 $\beta$, IL-6 and TNF- $\alpha$ in the hippocampus. Patients with hypothyroidism also present a significantly higher level of the inflammatory marker C-reactive protein (26). In addition, acute inflammation by lipopolysaccharide significantly increases the mRNA levels of COX-2 and reduces neurogenesis in the dentate gyrus (27). In a previous study (23), we demonstrated that treadmill exercise significantly increased COX-2 expression in the dentate gyrus of control and type 2 diabetic rats. In addition, treadmill exercise in COX-2 knockout mice significantly increased neurogenesis in the dentate gyrus (28). With colleagues, we have also demonstrated that COX-2 immunoreactivity was significantly increased in the hippocampus 3 weeks after streptozotocin treatment (29), while cell proliferation and neuroblast differentiation were significantly decreased at 3 weeks after streptozotocin treatment (30). The induction of COX-2 subsequently increases the synthesis of prostaglandin $\mathrm{E}_{2}\left(\mathrm{PGE}_{2}\right)$. The administration of $\mathrm{PGE}_{2}$ analogue increases the cell proliferation and differentiated neuroblasts in the subgranular zone (31). In addition, mRNA levels of G-protein coupled E-prostanoid receptors are highly expressed during neurogenesis (32). However, previous studies (33-35) have demonstrated that neuro-inflammation reduces neurogenic deficits. In addition, IL-6 suppresses neurogenesis and reduces hippocampal volume, skewing neural stem cells toward gliogenesis (36-38). 

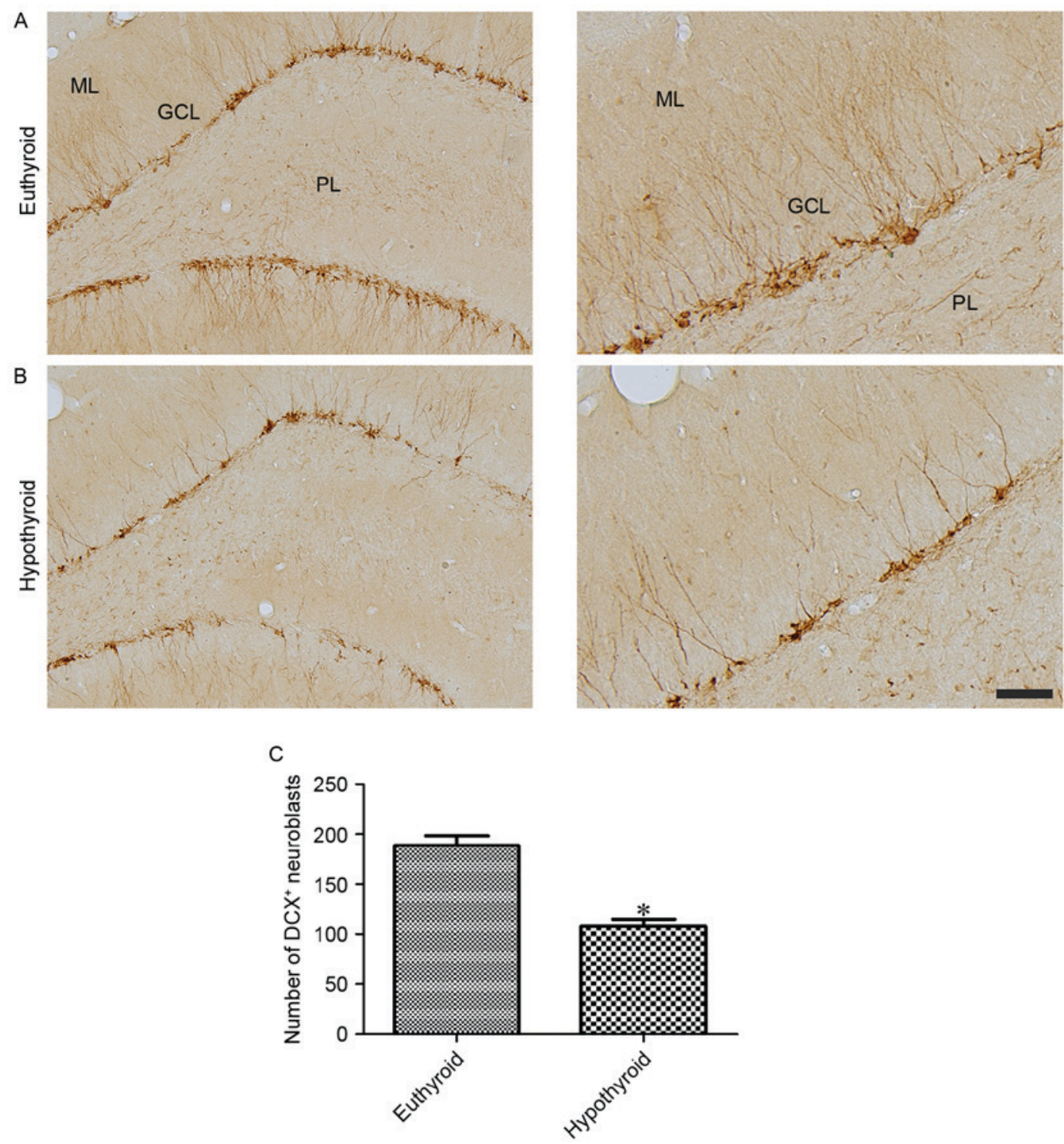

Figure 5. DCX immunoreactivity in the dentate gyrus of (A) euthyroid and (B) hypothyroid rats. DCX immunoreactive neuroblasts are present in the subgranular zone of dentate gyrus (cytoplasm) and their dendrites are extended into the ML of the dentate gyrus. There are fewer DCX immunoreactive neuroblasts and their dendrites in the hypothyroid rats compared with the euthyroid rats. Scale bar, $100 \mu \mathrm{m}$ (left) and $50 \mu \mathrm{m}$ (right). (C) Number of DCX-immunoreactive neuroblasts per section for each group. Differences between the means were analyzed using Student's $t$-test $\left(n=5\right.$ per group; ${ }^{*} \mathrm{P}<0.05$ vs. euthyroid). The bars represent the mean \pm standard error of means. DCX, doublecortin; ML, molecular layer; GCL, granule cell layer; PL, polymorphic layer.

In conclusion, adult-onset hypothyroidism significantly increases activation of the COX-2-mediated inflammation pathway and reduces the cell proliferation and neuroblast differentiation in the hippocampus. The present study proposed that COX-2-mediated inflammation is important as a candidate target for hippocampal impairment in the hypothyroidism. Future studies on the effect on the brain using a selective drug inhibitor or a genetic model of COX-2 are required for a better understanding of the importance of COX-2 in the hypothyroid condition.

\section{Acknowledgements}

The present study was supported by Basic Science Research Program through the National Research Foundation of Korea funded by the Ministry of Education (grant no. NRF-2015R1D1A1A01059314) and partially supported by the Research Institute for Veterinary Science, Seoul National University.

\section{Competing interests}

The authors declare that they have no competing interests.

\section{References}

1. Chan S and Kilby MD: Thyroid hormone and central nervous system development. J Endocrinol 165: 1-8, 2000.

2. Warner A and Mittag J: Thyroid hormone and the central control of homeostasis. J Mol Endocrinol 49: R29-R35, 2012.

3. Koromilas C, Liapi C, Schulpis KH, Kalafatakis K, Zarros A and Tsakiris S: Structural and functional alterations in the hippocampus due to hypothyroidism. Metab Brain Dis 25: 339-354, 2010.

4. de Jong FJ, den Heijer T, Visser TJ, de Rijke YB, Drexhage HA, Hofman A and Breteler MM: Thyroid hormones, dementia, and atrophy of the medial temporal lobe. J Clin Endocrinol Metab 91: 2569-2573, 2006. 
5. Ambrogini P, Cuppini R, Ferri P, Mancini C, Ciaroni S, Voci A Gerdoni E and Gallo G: Thyroid hormones affect neurogenesis in the dentate gyrus of adult rat. Neuroendocrinology 81: 244-253, 2005.

6. Desouza LA, Ladiwala U, Daniel SM, Agashe S, Vaidya RA and Vaidya VA: Thyroid hormone regulates hippocampal neurogenesis in the adult rat brain. Mol Cell Neurosci 29: 414-426, 2005.

7. Chaalal A, Poirier R, Blum D, Gillet B, Le Blanc P, Basquin M, Buée L, Laroche S and Enderlin V: PTU-induced hypothyroidism in rats leads to several early neuropathological signs of Alzheimer's disease in the hippocampus and spatial memory impairments. Hippocampus 24: 1381-1393, 2014.

8. Cao C, Matsumura K, Yamagata K and Watanabe Y: Induction by lipopolysaccharide of cyclooxygenase- 2 mRNA in rat brain; its possible role in the febrile response. Brain Res 697: 187-196, 1995.

9. Graham SH and Hickey RW: Cyclooxygenases in central nervous system diseases: A special role for cyclooxygenase 2 in neuronal cell death. Arch Neurol 60: 628-630, 2003.

10. Dubois RN, Abramson SB, Crofford L, Gupta RA, Simon LS, Van De Putte LB and Lipsky PE: Cyclooxygenase in biology and disease. FASEB J 12: 1063-1073, 1998.

11. Vane JR, Bakhle YS and Botting RM: Cyclooxygenases 1 and 2. Annu Rev Pharmacol Toxicol 38: 97-120, 1998.

12. Yamagata K, Andreasson KI, Kaufmann WE, Barnes CA and Worley PF: Expression of a mitogen-inducible cyclooxygenase in brain neurons: Regulation by synaptic activity and glucocorticoids. Neuron 11: 371-386, 1993.

13. National Research Council: Guide for the Care and Use of Laboratory Animals. National Acadamies Press, Washington, DC, 1996.

14. Cooper DS: Antithyroid drugs. N Engl J Med 311: 1353-1362, 1984

15. Paxinos G and Watson C: The Rat Brain in Stereotaxic Coordinates. Elsevier Academic Press, Cambridge, MA, 2007.

16. Ghenimi N, Alfos S, Redonnet A, Higueret P, Pallet V and Enderlin V: Adult-onset hypothyroidism induces the amyloidogenic pathway of amyloid precursor protein processing in the rat hippocampus. J Neuroendocrinol 22: 951-959, 2010.

17. O'Barr SA, Oh JS, Ma C, Brent GA and Schultz JJ: Thyroid hormone regulates endogenous amyloid-beta precursor protein gene expression and processing in both in vitro and in vivo models. Thyroid 16: 1207-1213, 2006.

18. Luo L and Stopa EG: Thyrotropin releasing hormone inhibits tau phosphorylation by dual signaling pathways in hippocampal neurons. J Alzheimers Dis 6: 527-536, 2004.

19. Sampaolo S, Campos-Barros A, Mazziotti G, Carlomagno S Sannino V, Amato G, Carella C and Di Iorio G: Increased cerebrospinal fluid levels of 3,3',5'-triiodothyronine in patients with Alzheimer's disease. J Clin Endocrinol Metab 90: 198-202, 2005

20. Kumihashi K, Uchida K, Miyazaki H, Kobayashi J, Tsushima T and Machida T: Acetylsalicylic acid reduces ischemia-induced proliferation of dentate cells in gerbils. Neuroreport 12: 915-917, 2001.

21. Nam SM, Kim JW, Yoo DY, Choi JH, Kim W, Jung HY, Won MH, Hwang IK, Seong JK and Yoon YS: Comparison of pharmacological and genetic inhibition of cyclooxygenase-2: Effects on adult neurogenesis in the hippocampal dentate gyrus. J Vet Sci 16: 245-251, 2015

22. Sasaki T, Kitagawa K, Sugiura S, Omura-Matsuoka E, Tanaka S, Yagita Y, Okano H, Matsumoto $\mathrm{M}$ and Hori M: Implication of cyclooxygenase-2 on enhanced proliferation of neural progenitor cells in the adult mouse hippocampus after ischemia. J Neurosci Res 72: 461-471, 2003.

23. Hwang IK, Yi SS, Yoo KY, Park OK, Yan B, Kim IY, Kim YN, Song W, Moon SM, Won MH, et al: Effects of treadmill exercise on cyclooxygenase- 2 in the hippocampus in type 2 diabetic rats: Correlation with the neuroblasts. Brain Res 1341: 84-92, 2010.
24. Yamashita A, Kunimatsu T, Yamamoto T and Yoshida K Hypothermic, but not normothermic, ischemia causes a drastic increase in cyclooxygenase-2 immunoreactive granule cells in rat dentate gyrus after 4 hours of ischemic reperfusion. Arch Histol Cytol 70: 197-205, 2007.

25. Zhang L, Blomgren K, Kuhn HG and Cooper-Kuhn CM: Effects of postnatal thyroid hormone deficiency on neurogenesis in the juvenile and adult rat. Neurobiol Dis 34: 366-374, 2009

26. Dizdarevic-Bostandic A, Burekovic A, Velija-Asimi Z and Godinjak A: Inflammatory markers in patients with hypothyroidism and diabetes mellitus type 1. Med Arch 67: 160-161, 2013.

27. Ma Y, Matsuwaki T, Yamanouchi $K$ and Nishihara $M$ : Glucocorticoids suppress the protective effect of cyclooxygenase-2-related signaling on hippocampal neurogenesis under acute immune stress. Mol Neurobiol 54: 1953-1966, 2017.

28. Nam SM, Kim JW, Yoo DY, Choi JH, Kim W, Jung HY, Won MH, Hwang IK, Seong JK and Yoon YS: Effects of treadmill exercise on neural stem cells, cell proliferation, and neuroblast differentiation in the subgranular zone of the dentate gyrus in cyclooxygenase- 2 knockout mice. Neurochem Res 38: 2559-2569, 2013.

29. Nam SM, Yi SS, Yoo DY, Kim W, Choi JH, Hwang IK, Seong JK and Yoon YS: Changes in cyclooxygenase-2 immunoreactivity in the hippocampus in a model of streptozotocin-induced type 1 diabetic rats. J Vet Med Sci 74: 977-982, 2012.

30. Choi JH, Hwang IK, Yi SS, Yoo KY, Lee CH, Shin HC, Yoon YS and Won MH: Effects of streptozotocin-induced type 1 diabetes on cell proliferation and neuronal differentiation in the dentate gyrus; correlation with memory impairment. Korean J Anat 42: 41-48, 2009.

31. Uchida K, Kumihashi K, Kurosawa S, Kobayashi T, Itoi K and Machida T: Stimulatory effects of prostaglandin E2 on neurogenesis in the dentate gyrus of the adult rat. Zoolog Sci 19: 1211-1216, 2002.

32. Tamiji J and Crawford DA: Prostaglandin E(2) and misoprostol induce neurite retraction in Neuro-2a cells. Biochem Biophys Res Commun 398: 450-456, 2010.

33. Ekdahl CT, Claasen JH, Bonde S, Kokaia Z and Lindvall O: Inflammation is detrimental for neurogenesis in adult brain. Proc Natl Acad Sci USA 100: 13632-13637, 2003.

34. Monje ML, Toda H and Palmer TD: Inflammatory blockade restores adult hippocampal neurogenesis. Science 302: 1760-1765, 2003.

35. Yang Y, Zhang M, Kang X, Jiang C, Zhang H, Wang P and Li J: Thrombin-induced microglial activation impairs hippocampal neurogenesis and spatial memory ability in mice. Behav Brain Funct 11: 30, 2015.

36. Nakanishi M, Niidome T, Matsuda S, Akaike A, Kihara T and Sugimoto H: Microglia-derived interleukin-6 and leukaemia inhibitory factor promote astrocytic differentiation of neural stem/progenitor cells. Eur J Neurosci 25: 649-658, 2007.

37. Balasubramaniam B, Carter DA, Mayer EJ and Dick AD: Microglia derived IL-6 suppresses neurosphere generation from adult human retinal cell suspensions. Exp Eye Res 89: 757-766, 2009.

38. Peng H, Sun L, Jia B, Lan X, Zhu B, Wu Y and Zheng J: HIV-1-infected and immune-activated macrophages induce astrocytic differentiation of human cortical neural progenitor cells via the STAT3 pathway. PLoS One 6: e19439, 2011.

This work is licensed under a Creative Commons Attribution-NonCommercial-NoDerivatives 4.0 International (CC BY-NC-ND 4.0) License. 